\title{
Prevalence of Bovine Tuberculosis in Sheep at Sadar and Parbatipur Upazila under Dinajpur District in Bangladesh
}

\author{
Ahmed Ali Omar1,2*, S. M. Harun-ur-Rashid33, Md. Haydar Ali3 ${ }^{3}$ Binti Abubakar Mohamed4 \\ ${ }^{1}$ Head of Lab at Someat Company, Mogadishu, Somalia \\ ${ }^{2}$ Faculty of Veterinary Science in Benadir University, Mogadishu, Somalia \\ ${ }^{3}$ Faculty of Veterinary and Animal Science Department of Pathology and Parasitology in Hajee Mohammad Danesh Science and \\ Technology University, Dinajpur, Bangladesh \\ ${ }^{4}$ Faculty of Veterinary Medicine and Animal Husbandry at Horsed International University, Mogadishu, Somalia \\ Email: *ahmaddvm18@gmail.com
}

How to cite this paper: Omar, A.A., Harun-ur-Rashid, S.M., Ali, Md.H. and Mohamed, B.A. (2021) Prevalence of Bovine Tuberculosis in Sheep at Sadar and Parbatipur Upazila under Dinajpur District in Bangladesh. Open Journal of Veterinary Medicine, 11, 315-326.

https://doi.org/10.4236/ojvm.2021.1111022

Received: August 27, 2021

Accepted: November 27, 2021

Published: November 30, 2021

Copyright $\odot 2021$ by author(s) and Scientific Research Publishing Inc. This work is licensed under the Creative Commons Attribution International License (CC BY 4.0).

http://creativecommons.org/licenses/by/4.0/

\section{(c) (i) Open Access}

\begin{abstract}
Tuberculosis is Zoonotic disease and infected animals continue to spread the disease to other animals and humans by excreting the germs in milk, meat, feces, and respiratory droplets, this study used bPPD (Bovine purified protein derivative) to observe TST (Tuberculin skin test) reactivity in the Sheep population in the Sadar and Parbatipur Upazilas of Dinajpur District. The research conducted from January to June of 2018. There is no history for sheep tuberculosis in the study area. Overall, 5 percent (7/140) of 140 sheep were positive, $15 \%(21 / 140)$ were doubtful, and $80 \%(112 / 140)$ were negative based on sex, age, breed, and body condition score, while lactation stage and reproduction status prevalence was 6.4 percent, 14.9 percent, and $78.7 \%$ positive, doubtful, and negative, respectively. Our findings suggest the presence of a skin test reaction response when employing the bPPD reagent, but this needs to be validated by pathological and serological techniques. Nevertheless, my preliminary investigation suggests that abattoirs must implement effective control systems and raise public awareness.
\end{abstract}

\section{Keywords}

Sheep, Tuberculosis, Tuberculin Skin Test, bPPD Reagent

\section{Introduction}

Sheep are the third most common ruminant species in Bangladesh, and they are 
largely employed for meat production. Bangladesh now has 1.69 million sheep [1]. Though the sheep were once restricted to specific sections of the country, they are now distributed throughout the country. Bangladesh's sheep are mostly indigenous, with only a few crossbreeds [2].

Tuberculosis (TB) is a contagious, infectious, granulomatous illness that affects a wide range of domestic and wild animals, as well as people [3] [4]. It is caused by Mycobacterium tuberculosis, Mycobacterium bovis, Mycobacterium bovis BCG strain, Mycobacterium caprae, Mycobacterium africanum, Mycobacterium microtianum, and Mycobacterium canetti [5] [6]. M. bovis, on the other hand, is the most widespread disease among mycobacteria, affecting a wide range of vertebrate animals of all ages, including humans. Cattle, goats, and pigs are the most susceptible, whereas sheep and horses have a high natural resistance [7] [8]. Infection occurs most commonly through inhalation, however infection can also occur through ingestion of infected substances [9] [10].

Tuberculosis (TB) in sheep has been reported in New Zealand, Sudan, Italy, Ireland, and the United Kingdom. Epidemiological studies have shown that tuberculosis in goats and sheep has a wide global distribution and has been reported in various countries around the world, including New Zealand, Sudan, Spain, Nigeria, the United Kingdom, Italy, Algeria, and Ethiopia [11] [12].

Tuberculosis is a chronic infection that develops granulomatous caseous inflammatory lesions in the lungs and associated lymph nodes in sheep, goats, and cattle in spontaneous infections, tuberculosis lesions can also be detected in the lymph nodes of the upper respiratory tract and other organs such as the spleen, liver, and mesenteric lymph nodes [13] [14].

Tuberculosis in animals is typically undetected, and infected animals continue to spread the disease to other animals and humans by excreting the germs in milk, meat, feces, and respiratory droplets, As a result, both animals and humans must be checked for tuberculosis prevalence in order to control the disease [15].

\section{Materials and Methods}

\subsection{Study Area and Duration}

The experiment plan was prepared in the Department of Pathology and Parasitology, Hajee Mohammed Danesh Science and Technology University (HSTU), Dinajpur, Bangladesh, and the study was done in Sadar and Parbatipur Upazila of Dinajpur District from January to June 2018.

Although most instances were missing for disease symptoms, the sample and sample size were selected randomly based on the availability of caserelated to sex, age, body condition, lactation, and reproduction status.

\subsection{Tuberculin Skin Testing (TST)}

The single intradermal tuberculin skin test (TST) is the most widely used TB screening test in the world; it is an internationally recognised standard for detecting $M$. bovis infection in live animals. 


\subsection{Procedure}

The tuberculin skin test (TST) is a single intradermal injection of bovine tuberculin purified protein Derivative (PPD), which is used to screen sheep for tuberculosis.

Tuberculin is a protein combination derived from cultures of the bacteria that causes tuberculosis. A little amount of bPPD is injected into the deep layer of the skin during the skin test. Before injecting tuberculin in the middle of the neck region, the skin was trimmed, shaved, and the thickness of the folds measured in millimeters with special calipers. The prepared site was then injected with $0.1 \mathrm{ml}$ bPPD using a tuberculin gun. The skin thickness response at the injection location is assessed after 72 hours, and the animal is classed as a positive, doubtful, or negative reactor.

\subsection{Reading of Response}

If an animal's immune system has already been "sensitized" by infection with $M$. bovis, tuberculin injection causes an inflammatory reaction and observed swelling at the injection site.

The swelling could be mild and edematous or firm and abrasive.

The results were interpreted according to OIE guidelines [16]:

1) A positive reactor is defined as a response that is $4.0 \mathrm{~mm}$ larger than the test.

2) The test is regarded suspect if the reaction is between 2.0 and $4.0 \mathrm{~mm}$.

3) If the reaction is less than $2.0 \mathrm{~mm}$, the test is negative.

Palpation at the injection site as well as observation revealed edema.

\section{Results}

Tuberculin Skin Test (TST) was used to screen 140 sheep of various ages, sexes, and breeds for tuberculosis. Clinical signs such as nasal discharge, diarrhea, and constipation have been recorded; however these indicators were not present in the majority of cases (Table 1 ).

Table 1. Tuberculin skin testing (TST) based on thickness of Skin before and after injection.

\begin{tabular}{cccccc}
\hline A & B & C & D & E & F \\
\hline $\begin{array}{c}\text { Sample } \\
\text { No. }\end{array}$ & Area & $\begin{array}{c}\text { Day (0) } \\
(\mathrm{mm})\end{array}$ & $\begin{array}{c}\text { Day 3 } \\
(\mathrm{mm})\end{array}$ & D-C (mm) & Result \\
\hline 1 & Sadar & $1.53 \mathrm{~mm}$ & $7 \mathrm{~mm}$ & $5.47 \mathrm{~mm}$ & Positive \\
2 & Parbutapur & $2.74 \mathrm{~mm}$ & $8 \mathrm{~mm}$ & $5.26 \mathrm{~mm}$ & Positive \\
3 & Parbutapur & $2.07 \mathrm{~mm}$ & $7.87 \mathrm{~mm}$ & $5.8 \mathrm{~mm}$ & Positive \\
4 & Sadar & $1.02 \mathrm{~mm}$ & $8 \mathrm{~mm}$ & $6.98 \mathrm{~mm}$ & Positive \\
5 & Parbutapur & $2.02 \mathrm{~mm}$ & $7.85 \mathrm{~mm}$ & $5.83 \mathrm{~mm}$ & Positive \\
6 & Sadar & $1 \mathrm{~mm}$ & $6.54 \mathrm{~mm}$ & $5.54 \mathrm{~mm}$ & Positive \\
7 & Parbutapur & $2 \mathrm{~mm}$ & $9 \mathrm{~mm}$ & $7 \mathrm{~mm}$ & Positive \\
\hline
\end{tabular}

$\mathrm{C}=$ Skin thickness before injection; $\mathrm{D}=$ Skin thickness after injection; $\mathrm{E}=$ Skin thickness response. 
The primary screening test for tuberculosis was a single intradermal tuberculin skin test (TST) with bovine PPD in the middle neck region, which is an internationally accepted standard for detecting $M$. bovis infection in live animals. Out of 140 sheep, 7 were found to be positive, and the average thickness day zero and third day were recorded then average tuberculin skin test response were examined.

According to Sex, females had the largest number of positive TB cases (6.4\%), while doubtful and negative cases were 14.9 percent and $78.7 \%$, respectively. Positive Cases in Male accounted for 2.2 percent, whereas Doubtful and negative cases were represented for 15.2 percent and 82.6 percent, respectively (Table 2 and Figure 1).

Sheep samples were divided into three age groups: under two years, between two and four years, and over four years. The highest prevalence of (23.5\%) was found in animals older than 4 years, followed by (4.1\%) in animals between 2 and 4 years of age, with no positive cases found in animals younger than 2 years of age (Table 3 and Figure 2).

According to the Breed, the Carole breed had the greatest positive rate (14.8\%), followed by non-descript Deshi (2.7\%), while doubtful and negative cases were 21 percent, 16.8 percent, 80.5 percent, and $77.7 \%$ for non-descript Deshi breeds and Carole Breed (Exotic breed), respectively (Table 4 and Figure 3).

According to their body condition, the score was divided into three categories: good, medium, and poor. Sheep with poor body condition had a higher frequency of tuberculosis (15\%) than sheep with a medium body condition $(2.7 \%)$. A good body condition scores were no responders to the bPPD reagent (Table 5 and Figure 4).

Table 2. Results of tuberculin skin test based on sex.

\begin{tabular}{cccccccc}
\hline \multirow{2}{*}{ Sex } & \multirow{2}{*}{$\begin{array}{c}\text { No of } \\
\text { observed }\end{array}$} & \multicolumn{2}{c}{ Positive Cases } & \multicolumn{2}{c}{ Doubtful Cases } & \multicolumn{2}{c}{ Negative Cases } \\
\cline { 3 - 8 } & No & $\%$ & No & $\%$ & No & $\%$ \\
\hline Male & 46 & 1 & 2.2 & 7 & 15.2 & 38 & 82.6 \\
Female & 94 & 6 & 6.4 & 14 & 14.9 & 74 & 78.7 \\
Total & 140 & 7 & $5 \%$ & 21 & $15 \%$ & 112 & $80 \%$ \\
\hline
\end{tabular}

Table 3. Results of tuberculin skin test based on age.

\begin{tabular}{cccccccc}
\hline \multirow{2}{*}{ Age } & No of & \multicolumn{2}{c}{$\begin{array}{c}\text { Positive } \\
\text { observed }\end{array}$} & \multicolumn{2}{c}{$\begin{array}{c}\text { Doubtful } \\
\text { Cases }\end{array}$} & \multicolumn{2}{c}{$\begin{array}{c}\text { Negative } \\
\text { Cases }\end{array}$} \\
\cline { 3 - 8 } & No & $\%$ & No & $\%$ & No & $\%$ \\
\hline$\leq 2$ years & 50 & 0 & 0 & 4 & 8 & 46 & 92 \\
$2<$ X < 4 years & 73 & 3 & 4.1 & 12 & 16.4 & 58 & 79.5 \\
X $\geq 4$ years & 17 & 4 & 23.5 & 5 & 29.5 & 8 & 47.1 \\
Total & 140 & 7 & 5 & 21 & 15 & 112 & 80 \\
\hline
\end{tabular}


Table 4. Results of tuberculin skin test based on breed.

\begin{tabular}{cccccccc}
\hline \multirow{2}{*}{ Type of Breed } & $\begin{array}{c}\text { No of } \\
\text { observed }\end{array}$ & \multicolumn{2}{c}{\begin{tabular}{c}
\multicolumn{2}{c}{ Cositive } \\
Cases
\end{tabular}} & \multicolumn{2}{c}{$\begin{array}{c}\text { Doubtful } \\
\text { Cases }\end{array}$} & \multicolumn{2}{c}{$\begin{array}{c}\text { Negative } \\
\text { Cases }\end{array}$} \\
\cline { 3 - 8 } & No & $\%$ & No & $\%$ & No & $\%$ \\
\hline $\begin{array}{c}\text { Non-descript } \\
\text { Deshi sheep }\end{array}$ & 113 & 3 & 2.7 & 19 & 16.8 & 91 & 80.5 \\
Carole Sheep & 27 & 4 & 14.8 & 2 & 7.4 & 21 & 77.7 \\
Total & 140 & 7 & 5 & 21 & 15 & 112 & 80 \\
\hline
\end{tabular}

Table 5. Results of tuberculin skin test based on body condition.

\begin{tabular}{cccccccc}
\hline \multirow{2}{*}{ Body Condition } & $\begin{array}{c}\text { No of } \\
\text { observed }\end{array}$ & \multicolumn{2}{c}{$\begin{array}{c}\text { Positive } \\
\text { Cases }\end{array}$} & \multicolumn{2}{c}{$\begin{array}{c}\text { Doubtful } \\
\text { Cases }\end{array}$} & \multicolumn{2}{c}{$\begin{array}{c}\text { Negative } \\
\text { Cases }\end{array}$} \\
\cline { 3 - 8 } & & No & $\%$ & No & $\%$ & No & $\%$ \\
\hline Good & 63 & 0 & 0 & 0 & 0 & 63 & 100 \\
Medium & 37 & 1 & 2.7 & 7 & 18.9 & 17 & 45.9 \\
Poor & 40 & 6 & 15 & 14 & 35 & 32 & 80 \\
Total & 140 & 7 & 5 & 21 & 15 & 112 & 80 \\
\hline
\end{tabular}

\begin{tabular}{|c|c|c|c|c|}
\hline \multirow{5}{*}{ 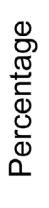 } & \multirow{5}{*}{$\begin{array}{r}100 \\
80 \\
60 \\
40 \\
20 \\
0\end{array}$} & & & \\
\hline & & & & \\
\hline & & & & \\
\hline & & & & \\
\hline & & Male & Female & Total \\
\hline & cases & 2.2 & 6.4 & 5 \\
\hline & l cases & 15.2 & 14.9 & 15 \\
\hline & e cases & 82.6 & 78.7 & 80 \\
\hline
\end{tabular}

Figure 1. Results of tuberculin skin test based on sex in percentage.

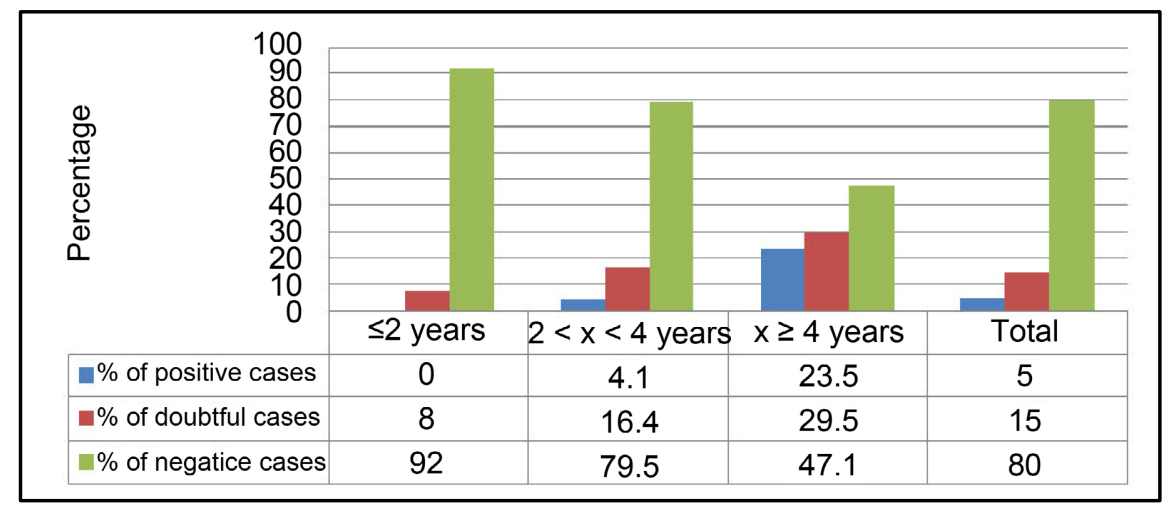

Figure 2. Results of tuberculin skin test based on age.

There were 140 sheep in all, 94 of which were females, 39 of which were lactating and 55 of which were dry (non-lactating). Positive cases of sheep TB were 10.2 percent in lactating females, compared to 3.6 percent in non-lactating fe- 
males, while highest doubtful cases were 23.1 percent in lactating females, compared to 9.1 percent in non-lactating females. Negative cases were 87.2 percent in non-lactating females, compared to 66.7 percent in lactating females (Table 6 and Figure 5).

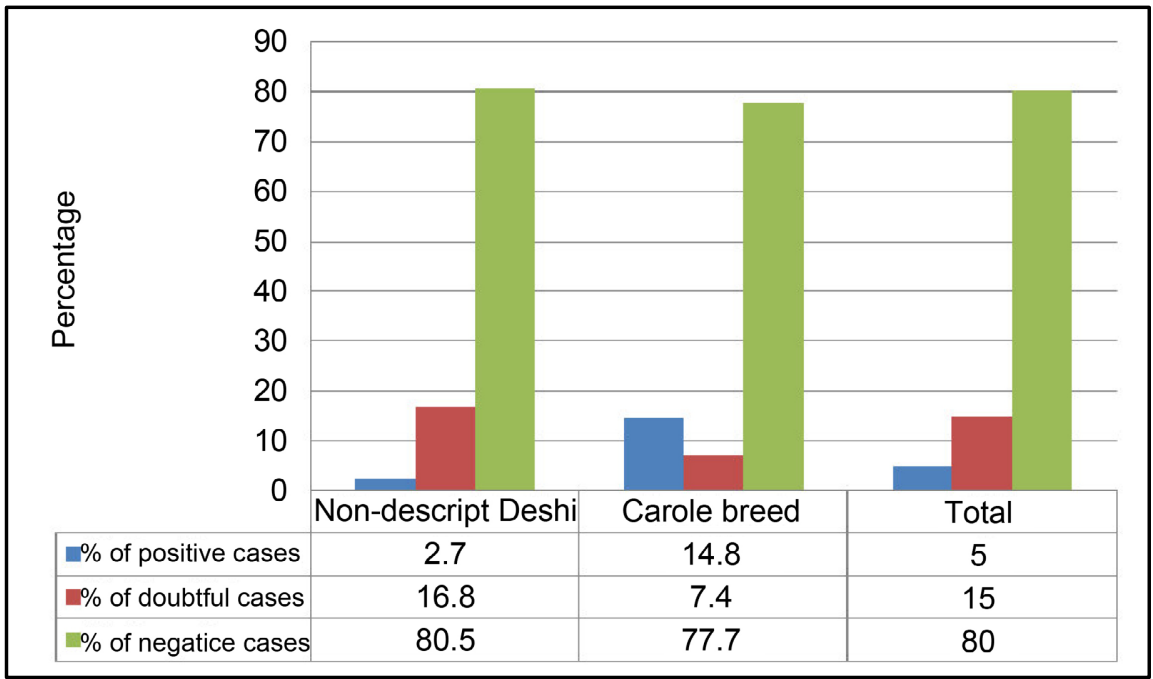

Figure 3. Results of tuberculin skin test based on breed in percentage.

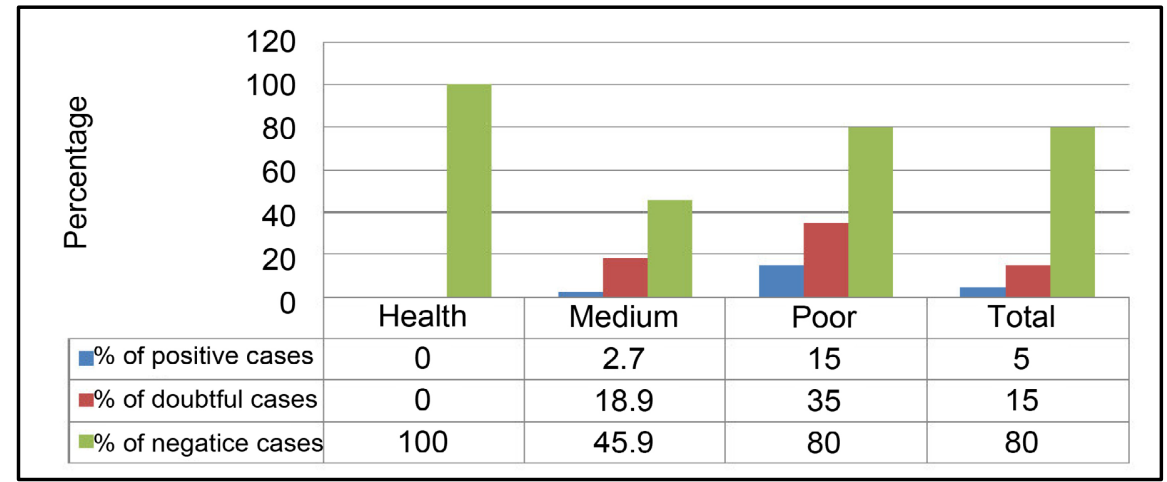

Figure 4. Results of tuberculin skin test based on body condition in percentage.

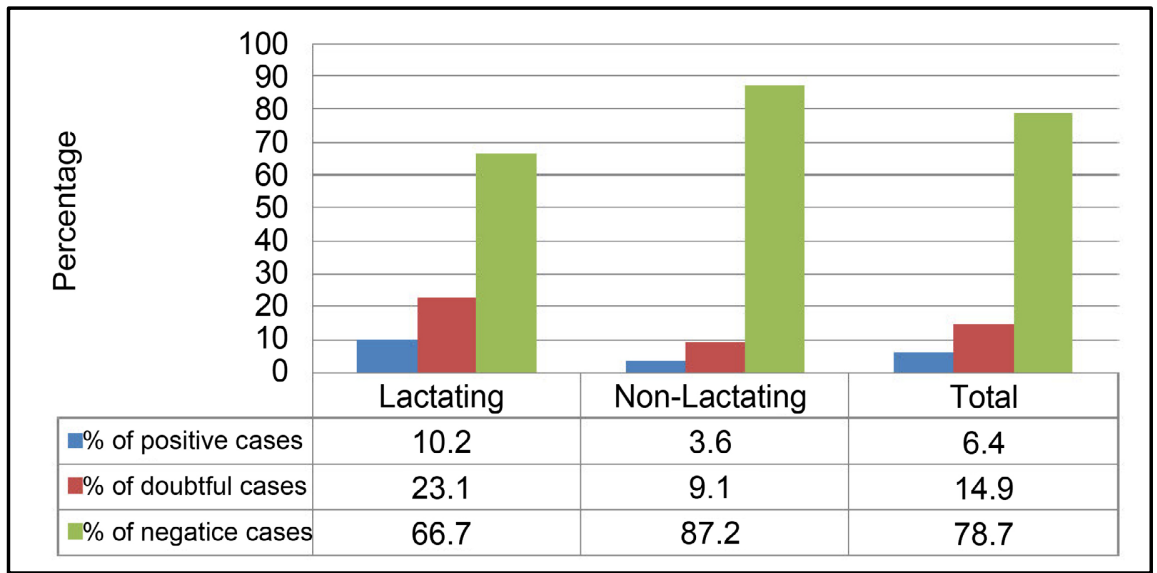

Figure 5. Results of tuberculin skin test based on lactating status in percentage. 
29 of the 94 ewes in the sample were pregnant, whereas 65 were not. Positive cases of tuberculosis were found $7.7 \%$ in pregnant ewes, compared to $6.9 \%$ in non-pregnant ewes, while highest doubtful cases were $37.9 \%$ in pregnant ewes, compared to 4.6 percent in non-pregnant ewes. Negative cases were 92.3 percent in non-pregnant ewes, compared to 44.8 percent in pregnant ewes (Table 7 and Figure 6).

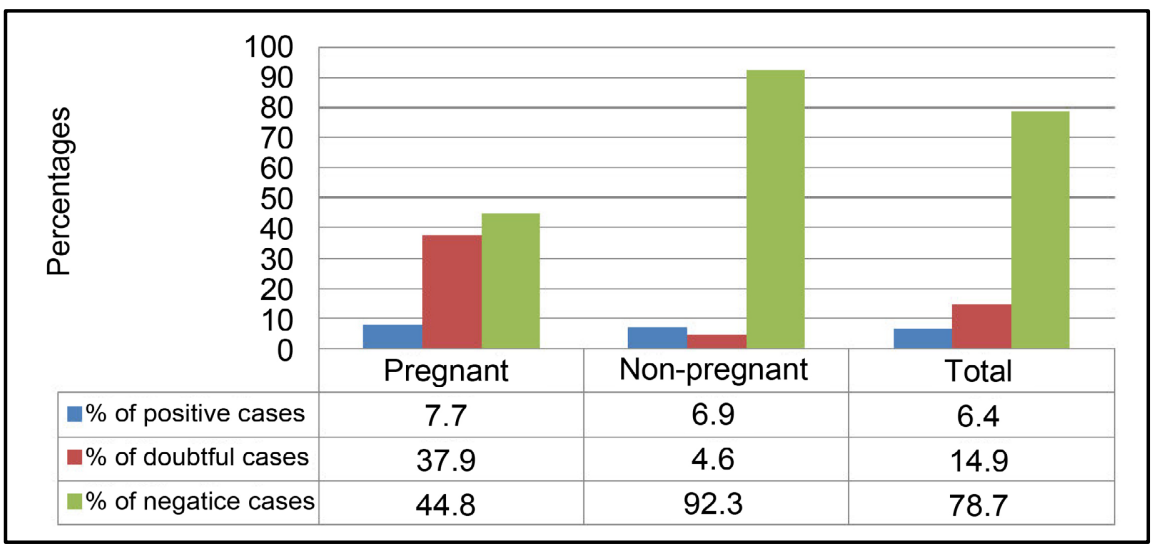

Figure 6. Results of tuberculin skin test based on reproduction status.

Table 6. Results of tuberculin skin test based on lactating status.

\begin{tabular}{cccccccc}
\hline \multirow{2}{*}{ Lactation Status } & $\begin{array}{c}\text { No of } \\
\text { observed }\end{array}$ & \multicolumn{2}{c}{\begin{tabular}{c}
\multicolumn{2}{c}{ Cositive } \\
Cases
\end{tabular}} & \multicolumn{2}{c}{$\begin{array}{c}\text { Doubtful } \\
\text { Cases }\end{array}$} & \multicolumn{2}{c}{$\begin{array}{c}\text { Negative } \\
\text { Cases }\end{array}$} \\
\cline { 3 - 8 } & & No & $\%$ & No & $\%$ & No & $\%$ \\
\hline Lactating & 39 & 4 & 10.2 & 9 & 23.1 & 26 & 66.7 \\
Non Lactating & 55 & 2 & 3.6 & 5 & 9.1 & 48 & 87.2 \\
Total & 94 & 6 & 6.4 & 14 & 14.9 & 74 & 78.7 \\
\hline
\end{tabular}

Table 7. Results of tuberculin skin test based on reproduction status.

\begin{tabular}{cccccccc}
\hline \multirow{2}{*}{$\begin{array}{c}\text { Production } \\
\text { status }\end{array}$} & $\begin{array}{c}\text { No of } \\
\text { observed }\end{array}$ & \multicolumn{2}{c}{$\begin{array}{c}\text { Positive } \\
\text { Cases }\end{array}$} & \multicolumn{2}{c}{$\begin{array}{c}\text { Doubtful } \\
\text { Cases }\end{array}$} & \multicolumn{2}{c}{$\begin{array}{c}\text { Negative } \\
\text { Cases }\end{array}$} \\
\cline { 3 - 8 } & & No & $\%$ & No & $\%$ & No & $\%$ \\
\hline $\begin{array}{c}\text { Pregnant } \\
\text { Non-pregnant }\end{array}$ & 65 & 5 & 7.7 & 11 & 37.9 & 13 & 44.8 \\
Total & 94 & 2 & 6.9 & 3 & 4.6 & 60 & 92.3 \\
\hline
\end{tabular}

\section{Discussions}

The overall prevalence in the current study was $5 \%$, which was higher than the previous study's 1.46 percent [17], which looked at the prevalence of bovine and avian tuberculosis in sheep and goats in Bangladesh. In addition, a study in Pakistan [18] found that the prevalence of tuberculosis in sheep was $2 \%$, and the 
overall percentage of reactor animals to SCCIT at farms in sheep and goats was 0.9 percent and 2.4 percent, respectively [19]. Asking sheep owners if they had encountered any cases of tuberculosis in sheep in the past provided information on the area's history of sheep tuberculosis, according to this information, there have been no previous cases of sheep tuberculosis in the area, except for a study [17] that looked into the incidence of bovine and avian tuberculosis in Bangladeshi sheep and goat populations, and another study [12] that used comparative intradermal tuberculin skin testing, postmortem examination, mycobacteriological culture, and molecular typing approaches to look into the epidemiology of tuberculosis in goats and sheep. Female sheep had a higher prevalence of tuberculosis (6.4 percent) than male sheep, according to this study ( 2.2 percent). This study supports [20], who found that females have a higher prevalence than males. [21] [22] [23] [24] also found that female animals had greater infection rates, which could be related to physiologic changes in immunological response during pregnancy and lactation, which could influence skin test responsiveness and perhaps lead to enhanced skin test detectability (Figures 7-10).

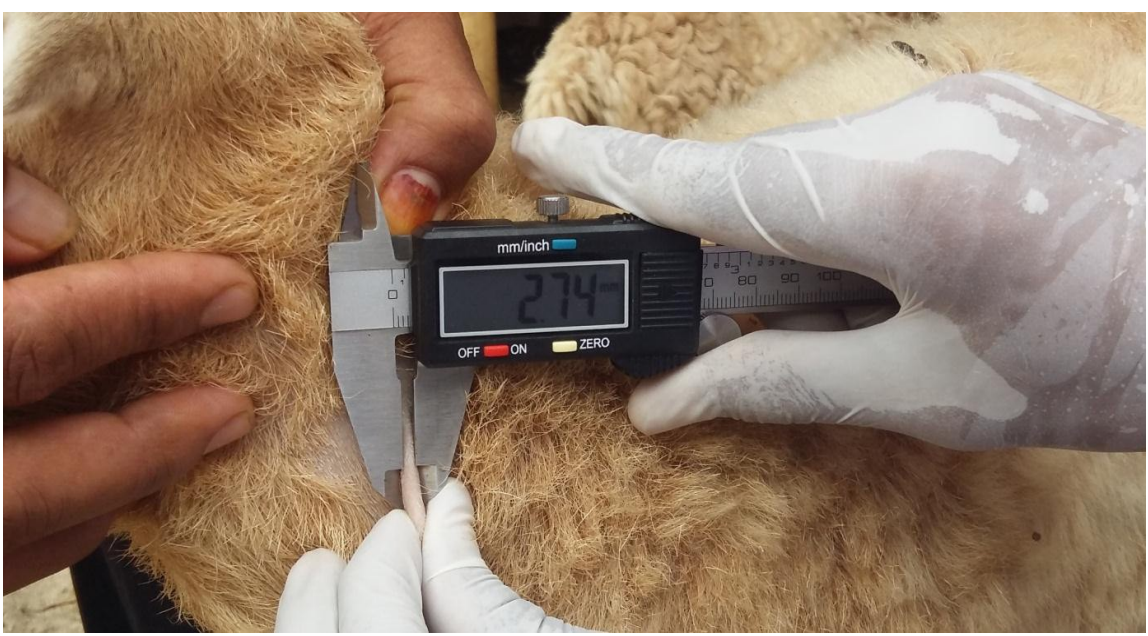

Figure 7. Skin thickness is measured before the tuberculin skin test is administered.

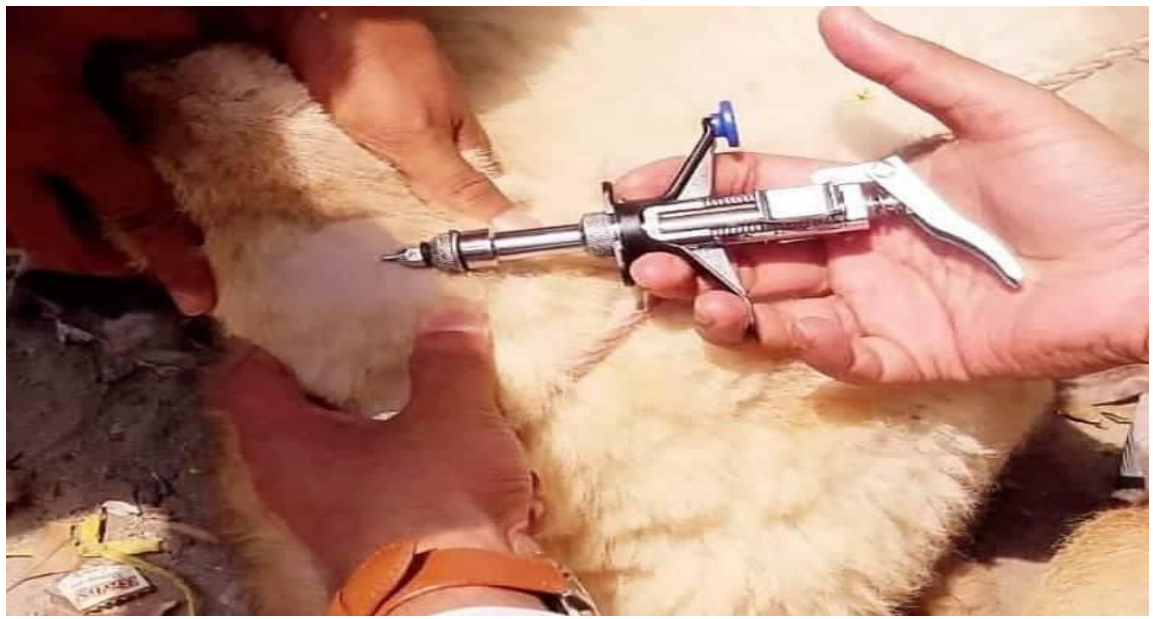

Figure 8. An injection for a bPPD skin test was given to a sheep's neck. 


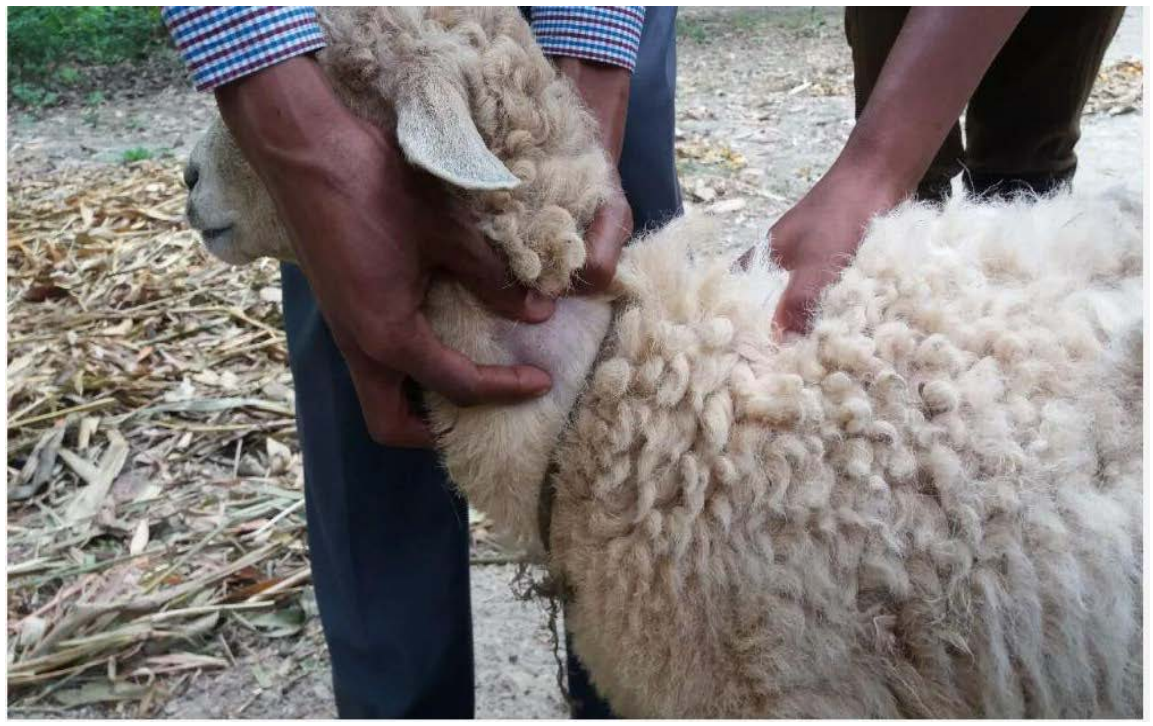

Figure 9. After 72 hours, a picture of a sheep showed a favorable reactive swelling.

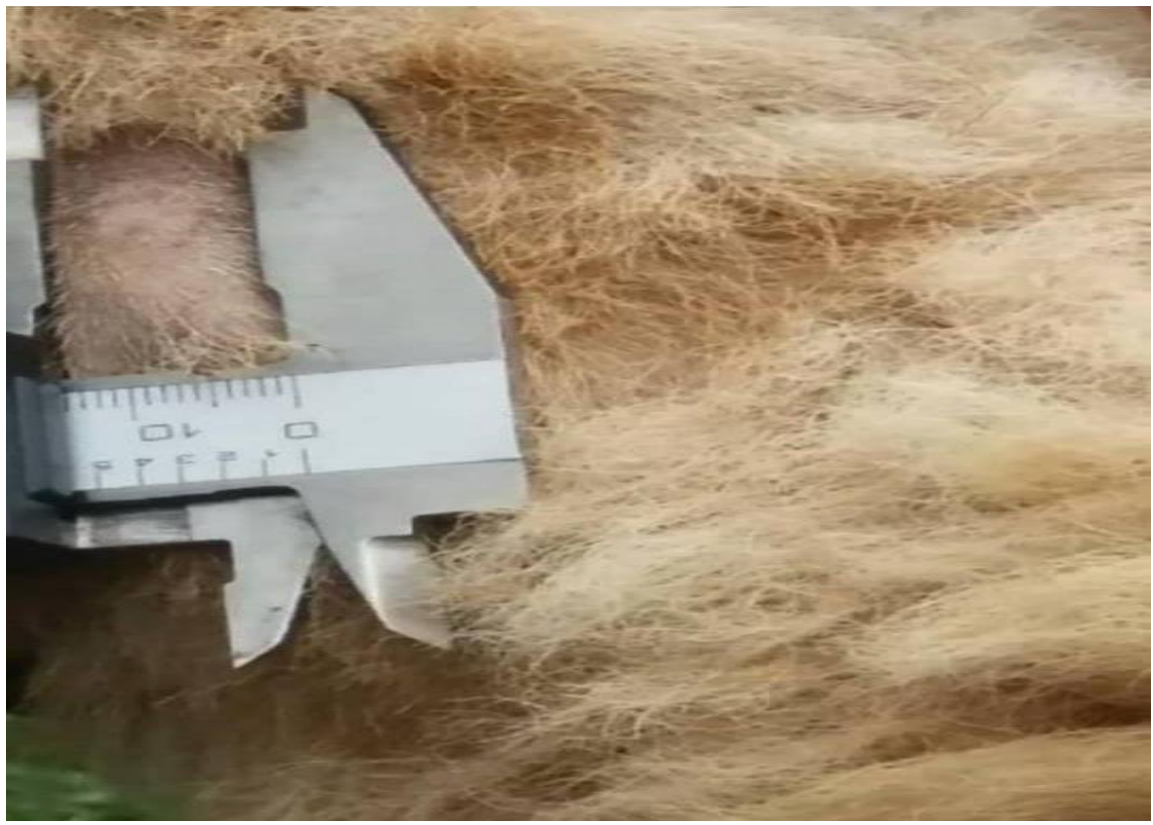

Figure 10. Skin thickness response measurement.

According to the findings of age, the prevalence of tuberculosis was 23.5 percent in animals older than 4 years and 4.1 percent in animals between 2 and 4 years of age, while no positive animals were found in animals younger than 2 years of age. [20] also discovered TB infection most commonly in adult and female animals, which is consistent with the findings of [12] [21] [24] [25] [26], who found a higher prevalence of tuberculosis in older and adult animals. Older goats and sheep also had a larger proportion of positive tuberculin test results, which could be connected to the fact that older animals are exposed to Mycobacterial infection for longer periods of time and more frequently. Similar findings have been reported in cattle, implying that the low incidence of positive 
cases in young animals may be attributable to the predominance of gamma delta $\mathrm{T}$ cells in calves, which have been shown to play a key role in anti-mycobacterial immunity [27]. Crossbreeds (14.8 percent) had a higher positive rate than non-descript Deshi breeds (2.7 percent) because of genetic variety among sheep are likely to influence susceptibility to $M$. bovis infection as well as differences in husbandry conditions [23]. Sheep with low body condition score had a higher prevalence of tuberculosis (15\%) than sheep with a medium body condition score $(2.7 \%)$ this finding is similar to that of [28], who found a 2.8-fold higher prevalence in animals in poor physical condition compared to animals in good health. However, animals in poor body condition scored had more positive skin test results than animals in good and medium body condition. This difference could be due to disease, seasonal climate change, or more or less pasture availability, as well as the prevalence of intestinal parasites.

Lactating ewes had a higher prevalence of tuberculosis (10.2 percent) than non-lactating ewes (55 percent) among 140 sheep, which is similar to the results of [23] which found lactating cows have a higher prevalence of 35.29 percent than non-lactating cows. 29 of the 94 ewes in the samples were pregnant, Positive cases of sheep Tuberculosis were found $7.7 \%$ of pregnant ewes, compared to $6.9 \%$ in non-pregnant ewes, Similar with findings, cattle disseminated cases, multiple small granuloma found in numerous organs including female genitalia, and also may be related to a feeding deficient ratio in which quantity and quality deficiency of the feed may contribute [23] [29].

\section{Conclusions}

The prevalence of sheep tuberculosis in the study population was $5 \%$. The presence of such a high prevalence indicates the possibility of infection transfer between animals, as well as from animals to humans and vice versa because the lack of an effective animal Tuberculosis surveillance system and vaccine use in animals, there is an urgent and unmet need for animal Tuberculosis control initiatives to be implemented in underdeveloped countries.

As Tuberculosis causative agents, Mycobacterium bovis, Mycobacterium avium, Mycobacterium tuberculosis, and non-tuberculosis mycobacterium, in this field of inquiry, further research is needed to understand potential epidemiological risk factors for infection and transmission between animals and also between animal and humans.

\section{Conflicts of Interest}

The authors declare no conflicts of interest regarding the publication of this paper.

\section{References}

[1] BBS (Bangladesh Bureau of Statistics) (2004) The Bangladesh Census of Agriculture (Rural) 1996, Structure of Agricultural Holdings and Livestock Population. Vol. 1, 
Bangladesh Bureau of Statistics, Dhaka.

[2] Bhuiyan, A.K.F.H (2006) Livestock Genetic Resources in Bangladesh: Preservation and Management. International Conference on Livestock Services, Chinese Academy of Agriculture Sciences (CAAS), Beijing, 17-19 April 2006, 5-74.

[3] O’Reilly L.M. and Daborn C.J. (1995) The Epidemiology of Mycobacterium bovis Infections in Animals and Man-A Review. Tubercle and Lung Disease, 76, 1-46. https://doi.org/10.1016/0962-8479(95)90591-X

[4] Daborn C.J., Grange J.M. and Kazwala R.R. (1996) Bovine Tuberculosis Cycle: An African Prospective. Journal of Applied Bacteriology, 81, 27S-32S. https://doi.org/10.1111/j.1365-2672.1996.tb04595.x

[5] Prodinger, W., Eigentler, A., Allerberger, F., Schonbauer, M. and Glawischnig, W. (2002) Infection of Red Deer, Cattle, and Humans with Mycobacterium bovis subsp. caprae in Western Austria. Journal of Clinical Microbiology, 40, 70-72. https://doi.org/10.1128/JCM.40.6.2270-2272.2002

[6] Erler, W., Martin, G., Sachse, K., Naumann, L., Kahlau, D., Beer, J., Bartos, M., Nagy, G., Cvetnic, Z., Zolnir-Dovc, M. and Pavlik, I. (2004) Molecular Fingerprinting of Mycobacterium bovis subsp. caprae Isolates from Central Europe. Journal of Clinical Microbiology, 42, 2234-2238. https://doi.org/10.1128/JCM.42.5.2234-2238.2004

[7] Radostits, O.M., Gay, C.C., Blood, D.C. and Hinchelift, K.W. (2000) Disease Caused by Bacteria: Mycobacterium. In: Veterinary Medicine: A Text Book of Disease of Cattle, Sheep, Pig, Goat and Horses, 9th Edition, Harcourt Publisher Ltd., London, 909-918.

[8] Thoen, C.O., Steele, J.H., Gilsdorf, M.J., Thoen, C. and Barletta, R. (2006) Pathogenesis of Mycobacterium bovis. In: Thoen, C.O., Steele, J.H. and Gilsdorf, M.J., Eds., Mycobacterium bovis Infection in Animals and Humans, Blackwell Publishing Ltd., Iowa, 18-33. https://doi.org/10.1002/9780470344538.ch4

[9] Neill, S.D., Bryson, D.G. and Pollock, J.M. (2001) Pathogenesis of Tuberculosis Incattle. Tuberculosis, 81, 79-86. https://doi.org/10.1054/tube.2000.0279

[10] Biet, F., Boschiroli, M., Thorel, M. and Guilloteau, L. (2005) Zoonotic Aspects ofMycobacterium bovis and Mycobacterium avium-intracellulare Complex (MAC). Veterinary Research, 36, 411-436. https://doi.org/10.1051/vetres:2005001

[11] Cordes, D.O., Bullians, J.A., Lake, D.E. and Carter, M.E. (1981) Observations on Tuberculosis Caused by Mycobacterium bovis in Sheep. New Zealand Veterinary Journal, 29, 60-62. https://doi.org/10.1080/00480169.1981.34798

[12] Kassa, G.M., Abebe, F., Worku, Y., Legesse, M., Medhin, G., Bjune, G. and Ameni, G. (2012) Tuberculosis in Goats and Sheep in Afar Pastoral Region of Ethiopia Andisolation of Mycobacterium tuberculosis from Goat. Veterinary Medicine International, 2012, Article ID: 869146. https://doi.org/10.1155/2012/869146

[13] Dean, G.S., Rhode, S.G., Coad, M., Whelan, A.O., Cockle, P.J.,Clifford, D.J., Hewinso, R.G. and Vordermeier, H.M. (2005) Minimum Infective Doses of Mycobacterium bovis in Cattle. Infectious Immunity, 73, 6467-6471. https://doi.org/10.1128/IAI.73.10.6467-6471.2005

[14] Daniel, R., Evans, H., Rolfe, S., De la Rua-Domenench, R., Grawshaw, T., Higgins, R.J., Schock, A. and Clifton, H.R. (2009) Outbreak of Tuberculosis Caused by $M y$ cobacterium bovis in Golden Guernsey Goats in Great Britain. Veterinary Record, 166, 335-342. https://doi.org/10.1136/vr.165.12.335

[15] Arunmozhivarman, K., Radhika, R., Kannan, P., Maroudam, V., Vijayalakshmi, K., Valentina Claudet, P. and Dhinakar Raj, G. (2018) Isolation and Identification of 
M.tuberculosis from Sheep Tissue Samples and Sero-Diagnosis Study in an Organized Sheep Farm. International Journal of Current Microbiology and Applied Sciences, 7, 2740-2744. https://doi.org/10.20546/ijcmas.2018.701.328

[16] Office International des Epizooties (2009) Manual of Diagnostic Tests and Vaccines for Terrestrial Animals. World Organization for Animal Health, Paris.

[17] Rahman, M.M., Rahman, K.M.F., Nazira Nhkhm, R.M. and Rahman, B. (2013) Prevalence of Bovine and Avian Tuberculosis in Sheep and Goat Population of Bangladesh. Scientific Journal of Microbiology, 2, 1-8.

[18] Ashraf, M., Khan, M.Z. and Chishti, M.A. (1986) Incidence and Pathology of Lungs Affected with Tuberculosis and Hydatidosis in Sheep and Goats. Pakistan Veterinary Journal, 6, 119-120.

[19] Javed, M.T., Munir, A., Shahid, M., Severi, G., Irfan, M., Aranaz, M., Cagiola, M. (2010) Percentage of Reactor Animals to Single Comparative Cervical Intradermaltuberculin (SCCIT) in Small Ruminants in Punjab Pakistan. Acta Tropica, 113, 88-91. https://doi.org/10.1016/j.actatropica.2009.08.026

[20] Salgado, M., Herthnek, D., Bölske, G., Leiva, S. and Kruze, J. (2009) First Isolation of Mycobacterium avium Subsp. Paratuberculosis from wild Guanacos (Lama Guanicoe) on Tierra Del Fuego Island. Journal of Wildlife Diseases, 45, 295-301. https://doi.org/10.7589/0090-3558-45.2.295

[21] Phaniraja, K.L., Jayaramu, G.M., Sanganal, J. and Kumar, N.G.S. (2010) Incidence of Tuberculosis in and around Banglore. Veterinary World, 3, 161-164.

[22] Nwanta, J.A., Umeononigwe, C.N., Abonyi, G.E. and Onunkwo, J.I. (2011) Retrospective Study of Bovine and Human Tuberculosis in Abattoirs and Hospitals in Enugu State, Southeast Nigeria. Journal of Public Health and Epidemiology, 3, 329-336.

[23] Arshad, M., Ifrahim, M., Ashraf, M., Rehman, S.U. and Khan, H.A. (2012) Epidemiological Studies on Tuberculosis in Buffalo Population in Villages around Faisalabad. Journal of Animal and Plant Sciences, 22, 246-249.

[24] Trangadia, B.J., Rana, S.K. and Srinivasan, V.A. (2013) Prevalence of Bovine Tuberculosis in Organized Dairy Farm. Indian Journal of Veterinary Pathology, 37, $72-74$.

[25] Khan, M.A. (1996) TB: Need to Revitalize Its Control Programme in Pakistan. Journal of College of Physicians and Surgeons Pakistan, 6, 1-3.

[26] Sharma, S., Patil, P.K., Kumar, H., Mahajan, V., Filia, G., Verma, S., et al. (2011) Bovine Tuberculosis in Intensive Dairy Operations of Punjab: Longitudinal Comparative Study on Prevalence and the Associated Risk Factors. Indian Journal of Comparative Microbiology Immunology and Infectious Diseases, 32, 41-44.

[27] Moiane, I., Machado, A., Santos, N., Nhambir, A., Inlamea, O., et al. (2014) Prevalence of Bovine Tuberculosis and Risk Factor Assessment in Cattle in Rural Livestock Areas of Govuro District in the Southeast of Mozambique. PLOS ONE, 9, e91527. https://doi.org/10.1371/journal.pone.0091527

[28] Rahman, M.M. and Samad, M.A. (2008) Prevalence of Bovine Tuberculosis and Its Effects on Milk Production in Red Chittagong Cattle. Bangladesh Journal of Veterinary Medicine, 6, 175-178. https://doi.org/10.3329/bjvm.v6i2.2332

[29] The Centre for Food Security and Public Health (2009) Bovine Tuberculosis. http://www.cfsph.iastate.edu/Factsheets/pdfs/bovine_tuberculosis.pdf 